\title{
Produzir conhecimento é um pensar militante
}

\author{
Producir conocimiento es tener un pensamiento militante \\ Producing knowledge is creating a militant thought
}

\author{
Luiz Fernandes de Oliveira ${ }^{1} \quad$ Liliam do Carmo Oliveira Cunha ${ }^{2}$ \\ Recibido:21/11/2016 / Aprobado:7/3/2017
}

Como seria a condição humana se não houvesse militantes? Não porque os militantes sejam perfeitos, porque tenham sempre a razão, porque sejam super-homens e não se equivoquem. Não é isso.

É que os militantes não vêm para buscar o seu, vem entregar a alma por um punhado de sonhos.

Ao fim e ao cabo, o progresso da condição humana depende fundamentalmente de que exista gente que se sinta feliz em gastar sua vida a serviço do progresso humano.

Ser militante não é carregar uma cruz de sacrifício. É viver a glória interior de lutar pela liberdade em seu sentido transcendente".

José Pepe Mujica

\begin{abstract}
Resumo
O que refletiremos neste texto vai de encontro ao que o estudo das relações étnico-raciais na educação no Brasil tem demostrado nos últimos anos, ou seja, não há possibilidade de construção do conhecimento se não tivermos uma postura militante e engajada. Esta postura, não é novidade nas ciências da educação ou nas ciências sociais. Veremos, através de análise bibliográfica, como pensadores e pesquisadores militantes e engajados nos demonstram que o conhecimento se produz na militância e no engajamento. Esta última afirmação, extremamente polêmica nos meios acadêmicos, quer debater com a ideia hegemônica de que para ser científico e objetivo, o sujeito que se envolve com a produção do conhecimento, só o fará se for alçado como sujeito epistêmico, mensageiro de um modo preciso de investigar, armado com conceitos que o direcionam na ação sobre a empiria e na explicação como segurança de objetividade do conhecimento produzido, como aquele que produz verdades e sentidos para a sociedade. Entretanto, como veremos em nossa argumentação, também epistêmica, os sujeitos produtores de conhecimento são mobilizados por uma inquietação intelectual, que tem sua matriz na realidade concreta em que os mesmos estão implicados. Este termo aqui posto pode ser analogamente situado naquilo que Freire (1987) nos diz sobre o fato de que a cultura não pode ser arrancada do sujeito, pois este só existe porque a cultura lhe é constitutiva. Este sujeito de cultura é seu próprio produtor. Implicado em sua realidade, este sujeito não tem como ser objetivado para fora de si.
\end{abstract}

Palavras chaves: conhecimento, epistemologias, militância, educação e relações raciais.

\footnotetext{
"Este texto corresponde con la temática de la ponencia presentada en el III Seminario Internacional Culturas y Desarrollo, III Encuentro de la Red de Interculturalidad, IV Encuentro de la Red de Trabajo con Pueblos Indígenas, IV Encuentro sobre Sociedades en Cambio, Territorios, Culturas y Buen Vivir, Desafíos desde las identidades y Saberes Diversos, realizado el 20, 21 y 22 de julio de 2016, en la Universidad Nacional, campus Omar Dengo, Heredia y en la Universidad de Costa Rica, Sede de Occidente, San Ramón, ahora en formato de artículo científico, en versión completa extendida.

${ }^{1}$ Doctor en Educación por la Pontificia Universidad Católica de Rio de Janeiro - PUC, Profesor del Programa de Postgrado en Educación, Contextos Contemporáneos y Demandas Populares - PPGEDUC / Universidad Federal Rural de Rio de Janeiro y de la Licenciatura en Educación del Campo de la UFRRJ. Brasil. Miembro del Grupo de Investigación en Políticas Públicas, Movimientos Sociales y Culturas. Correo electrónico: axeluiz@gmail.com

${ }^{2}$ Máster en Educación, contextos y popular contemporánea exige por la Universidad Federal Rural de Río de Janeiro - UFRRJ, Supervisor de la Fundación Escuela de Educación Soporte Técnico - FAETEC. Brasil. Miembro del Grupo de Investigación en Políticas Públicas, Movimientos Sociales y Culturas. Correo electrónico: liliandocarmo.dde@gmail.com
} 
Resumen

Lo que reflexionaremos en este texto va en contra de lo que el estudio de las relaciones étnico-raciales en la educación en Brasil ha demostrado en los últimos años, es decir, no hay posibilidad de construcción de conocimiento si no tuviéramos una postura militante y comprometida. Esta postura, no es nada nuevo en las ciencias de la educación o en ciencias sociales. Vamos a ver, a través del análisis bibliográfico, como pensadores e investigadores militantes y comprometidos nos demuestran que el

Conocimiento se produce en la militancia y en el compromiso. Esta última afirmación, muy polémica en el ámbito académico, quiere discutir con la idea hegemónica de que para ser científico y objetivo, el individuo que se involucra con la producción de conocimiento, sólo lo hará si se plantea como sujeto epistémico, mensajero de una forma precisa de investigar, armado con conceptos que lo conducen a la acción sobre la experiencia sensible y en la explicación como seguridad de objetividad del conocimiento producido, como el que produce verdades y significados para la sociedad. Sin embargo, como veremos en nuestro argumento, también epistémico, los individuos productores de conocimiento son movilizados por una inquietud intelectual, que tiene origen en la realidad concreta en que están implicados. La discusión aquí presentada puede ser igualmente situada en lo que Freire (1987) nos dice sobre el hecho de que la cultura no puede ser quitada del individuo, pues él solo existe porque la cultura le es constitutiva. Este individuo de cultura es su propio productor. Implicado en su realidad, este individuo no tiene como ser objetivado para fuera de sí mismo.

Palabras clave: conocimiento, epistemologías, militancia, educación y relaciones raciales.

\title{
Abstract
}

\begin{abstract}
This paper discusses the way ethnic-racial relationships are built in Brazilian education, that is, new knowledge cannot be constructed if an engagement posture and activist attitude is created. This posture is not new in education and social sciences. A literature review points out that, researchers and thinkers demonstrate that knowledge is produced by activism and engagement. It challenges a hegemonic idea of knowledge production. Therefore, to be considered a scientist, it has to be in an elevated epistemic subject, a messenger of a particular way of investigation with specific concepts that direct an empirical action. Acting as guarantor for objectivity of the produced knowledge, as the one who produces truths and meaning for society epistemically. The knowledge of producing subjects is moved by intellectual anxiety based on a concrete reality in which it is embedded. This term can be analogously situated in what Freire (1987) points out that culture cannot be unlinked from the subject, as it is the culture that constitutes the subject. This cultural subject is an own producer, implied in a reality; this subject cannot be objectivized outward itself.
\end{abstract}

Key-words: Knowledge, epistemologies, social activism, education and race relations

\section{Introdução}

Segundo o dicionário Aurélio, o termo militante significa aquele que milita. Que atua, que participa. Ou, membro ativo de uma causa, que se posiciona de uma forma similar àquela ideologia, trabalho, profissão, causa, envolvido diretamente, ativamente e se identifica através de sua postura pessoal. Outro termo similar é engajado. Aquele que filia-se a uma linha ideológica, filosófica e que se coloca a serviço de uma ideia, de uma causa, de uma coisa. Ser militante ou engajado significa, enfim, ter uma postura de vida em que o sujeito luta por uma causa e dedica boa parte de sua vida na busca de seus objetivos, sejam eles políticos, sociais, culturais, econômicos ou religiosos.
Nas ciências sociais e da educação aprendemos que não podemos ser militantes em nossas pesquisas, isto por que aquilo que estudamos e pesquisamos devem ser objetos de análise, ou seja, ter um caráter analítico e não normativo, pois a pesquisa tem como horizonte saber investigar aquilo que não conhecemos e não aquilo que queremos para nossas vidas.

$\mathrm{Na}$ esteira dessa concepção se encontra o significado daquilo que diversos cientistas denominam de neutralidade axiológica. Ou seja, a postura científica exige a isenção de valores numa investigação, nenhum procedimento científico 
pode conter uma resposta sobre a desejabilidade de uma coisa. A natureza da ciência é testar, experimentar sem um julgamento de valor de quem está investigando.

O que refletiremos neste texto vai de encontro ao que o estudo das relações étnicoraciais na educação tem demostrado nos últimos anos, ou seja, não há possibilidade de construção do conhecimento se não tivermos uma postura militante e engajada. Esta postura individual e coletiva, não é novidade nas ciências da educação ou nas ciências sociais. Veremos como pensadores e pesquisadores militantes e engajados nos demonstram que o conhecimento se produz na militância e no engajamento. Como veremos em nossa argumentação, também epistêmica, os sujeitos produtores de conhecimento são mobilizados por uma inquietação intelectual, que tem sua matriz na realidade concreta em que o mesmo está implicado. Este termo pode ser analogamente situado naquilo que Paulo Freire (1987) nos diz sobre o fato de que a cultura não pode ser arrancada do sujeito, pois este só existe porque a cultura lhe é constitutiva. Implicado em sua realidade, este sujeito não tem como ser objetivado para fora de si.

Os sujeitos, vivendo em sociedades, não são livres das lógicas do poder, das ideologias ou dos afetos. Ao analisar algo, situações ou coisas, ele aplica ao mesmo tempo um valor, útil ou necessário ao seu grupo de pertencimento ou sociedade a qual está inserido no seu tempo histórico.

\section{A neutralidade axiológica e suas raízes}

A ideia de neutralidade axiológica tem sua raiz naquilo que Quijano (1992) denomina de Colonialidade, ou seja, a operação política e epistêmica que, a partir da dominação colonial das Américas, afirmou uma dominação colonial, forjando uma complexa concepção cultural denominada racionalidade, estabelecendo um paradigma universal de conhecimento, onde existe uma humanidade racional (a Europa) e o resto do mundo.

Para Castro-Gómez, a colonialidade ainda existente, mesmo com o fim do colonialismo, faz referência a um tipo hegemônico de produção do conhecimento que ele denominou de "la hybris del punto cero" referindo-se a uma forma de conhecimento humano que possui pretensões de objetividade e cientificidade partindo do pressuposto de que o observador não forma parte do observado. Para este autor:

(...) o ponto zero é o princípio epistemológico absoluto, mas também o controle social e econômico do mundo. Segue a necessidade que teve o Estado espanhol (e logo depois as demais potências hegemônicas do sistema mundo) para eliminar qualquer sistema de crença que não favoreceu a visão capitalista do homus economicus. Já não poderiam coexistir diferentes formas de "ver o mundo", mas se deveria taxonomizá-las de acordo com uma hierarquia de tempo e espaço. As outras formas de conhecer foram declaradas como pertencentes ao "passado" da ciência moderna, como "doxa" que enganava os sentidos, como "superstição" que impediam a passagem para a "maioridade", como "obstáculo epistemológico" para a obtenção da certeza. A partir da perspectiva do ponto zero, os conhecimentos humanos foram ordenados em uma escala epistemológica que vai desde o tradicional até o moderno, desde a barbárie até a civilização, desde a comunidade até o indivíduo, desde a tirania até a democracia, desde o individual até o universal, desde o oriente até o ocidente. Estamos, então, diante de uma estratégia epistêmica de domínio (...) (Castro-Gómez, 2005, p. 63-64).

A crítica de Castro-Gómez chega à conclusão de que a epistemologia europeia se fundamentou na projeção em um sujeito cognoscitivo transcendental e em um sujeito empírico europeu, que é branco, masculino, heterossexual e pertencente à classe 
média. Destaca ainda que é uma ilusão observar e capturar uma totalidade se não se leva em consideração o próprio lócus de observação. Neste sentido, a epistemologia moderna se construiu presumindo uma perspectiva universal de observação e um lócus privilegiado de enunciação cego para a observação de seu próprio lócus.

Dussel (2009) argumenta que toda a filosofia moderna fecha-se numa reflexão sobre o conhecimento puramente centrada na Europa. E mais, confirma a pretensão europeia de objetividade e a íntima relação entre o "ego cogito" e o "ego conquiro", citando alguns dos principais filósofos europeus:

O ser humano adquire confiança em si mesmo. Com a invenção da pólvora desaparece da guerra a inimizade individual. O homem descobre a América, os seus tesouros e os seus povos, descobre a natureza, descobre-se a si mesmo (Hegel, 1970, v. 20, p. 62, apud Dussel, 2009, p. 287).

Será sempre justo e conforme ao direito natural que tais gentes [os indígenas das Américas] se submetam ao império de príncipes e nações mais cultas e humanas, para que, pelas suas virtudes e pela prudência de suas leis, abandonem a barbárie e se submetam a uma vida mais humana e ao culto da virtude (Gines de Sepúlveda [renascentista], 1967, p. 85, apud Dussel, 2009, p. 296).

Portanto, a construção do conhecimento filosófico se realiza como cânone e tradição que silenciam a produção de outros conhecimentos fora da Europa (Mignolo, 2003). Esta afirmação leva a outras: a constituição das categorias de colonialidade do saber e racismo epistêmico.

Quijano fala da colonialidade do saber, entendida como a repressão de outras formas de produção de conhecimento não europeus que nega o legado intelectual e histórico de povos indígenas e africanos, por exemplo, reduzindo-os, por sua vez, à categoria de primitivos e irracionais, pois pertencem a uma "outra raça”. Esta ideia é bem ilustrada naquilo que Praxedes (2008) denomina de aspectos eurocêntricos e racistas nas obras dos mais reconhecidos pensadores considerados clássicos das ciências sociais, como Kant, Hegel, Marx, Tocqueville, Durkheim, Comte etc.

Toda esta hegemonia epistemológica da modernidade europeia se traduz num racismo epistêmico, ou, como afirma Grosfoguel (2007), sobre como a "(...) epistemologia eurocêntrica ocidental dominante não admite nenhuma outra epistemologia como espaço de produção de pensamento crítico nem científico" (p. 35).

Mignolo (2003) escreve que os espanhóis julgavam e hierarquizavam a inteligência e a civilização dos povos tomando como critério a escrita alfabética. Porém, no século XVIII e XIX, o critério de avaliação passa a ser a História. Ou seja, os povos "sem História" situam-se em um tempo "anterior" ao "presente". Assim, com base na colonialidade do poder:

(...) o eurocentrismo torna-se, portanto, uma metáfora para descrever a colonialidade do poder, na perspectiva da subalternidade. Da perspectiva epistemológica, o saber e as Histórias locais européias foram vistos como projetos globais, desde o sonho de um Orbis universalis christianus até a crença de Hegel em uma História universal, narrada de uma perspectiva que situa a Europa como ponto de referência e de chegada (2003, p. 41).

Para Mignolo, a expansão ocidental após o século XVI não foi somente econômica e religiosa, mas também a expansão das formas hegemônicas de conhecimento e de um conceito de representação do conhecimento e cognição impondo-se como hegemonia epistêmica, política e historiográfica, estabelecendo assim a colonialidade do saber.

Se a colonialidade do poder criou uma espécie de fetichismo epistêmico (ou seja, a cultura, as ideias e conhecimentos dos colonialistas aparecem 
de forma sedutora que se busca imitar), impondo a colonialidade do saber sobre os não europeus, se evidenciou também uma geopolítica do conhecimento, ou seja, o poder, o saber e todas as dimensões da cultura se definiam a partir de uma lógica de pensamento localizado na Europa.

Para Mignolo (2003) a presunção de considerar a América Latina como o "outro", por exemplo, pode explicar as sucessivas construções de exterioridade nas Histórias coloniais e, por consequência, as similaridades entre outras regiões (Mundo Árabe, África negra, Índia, Sudeste Asiático e China). Dussel (1990) faz a conexão desta ideia, fundamentando a Colonialidade do saber com o pensamento moderno pós Descartes, que pressupunha uma ontologia de totalidade enquanto metafísica da alteridade como negatividade.

Quando se formula o conceito de que a Colonialidade do saber, na afirmação de que a Europa se constituiu como racional e pode ter sujeitos enquanto as outras culturas não são racionais, está se formulando também a ideia de que há uma correlação entre epistemologia e economia, por um lado, e, por outro, entre epistemologia e colonização, na medida em que a constituição da Europa como entidade geopolítica se realiza a partir da qual se mede, se estuda e se classifica o resto do mundo.

Esta afirmação claramente se expressa numa célebre e já consagrada formulação de Marx Weber:

Sendo produto da moderna civilização europeia, o estudioso de qualquer problema da História universal não pode deixar de indagar a que conjunto de circunstâncias deve atribuir-se o fato de que na civilização ocidental, e nela apenas, surgiram fenômenos culturais que (como nos apraz pensar) traçam uma linha de desenvolvimento dotada de valor e significação universal.
Somente no Ocidente existe uma ciência num grau de desenvolvimento que hoje reconhecemos como válido. Resumindo, conhecimento e observações de grande sofisticação já existiram em outras partes do mundo, sobretudo na Índia, China, Babilônia, Egito. Mas na Babilônia e em outros lugares faltava à astronomia - o que torna seu desenvolvimento tanto mais espantoso - a base matemática que, pela primeira vez, lhe forneceram os gregos. A geometria indiana carecia de prova racional... Às ciências naturais indianas faltava o método experimental (Weber, 1992, p. 13).

Enfim, através da Colonialidade do saber, as dimensões constitutivas dos conhecimentos locais modernos (europeus) construíram uma eficácia naturalizadora perante o mundo não europeu. $\mathrm{O}$ curioso é que esta naturalização é cega a processos históricos fora da Europa, realidade que espanta os mais críticos e aqueles estudiosos abertos a possibilidade da crítica se escandalizam com certas interpretações históricas que beiram ao grotesco, como, por exemplo, este relato:

Ao estudar os conhecimentos astronômicos dos Dogon ${ }^{3}$ nos anos 40, [do século XX] Marcel Griaule e os seus discípulos ficaram fascinados com o nível de conhecimentos existente. Recentemente, o conhecido astrônomo Carl Sagan, da Universidade Cornell de Nova Iorque, decidiu avaliar esses mesmos conhecimentos Dogon, e concluiu que os 'Dogon, em contraste com todas as sociedades pré-científicas, sabiam que os planetas, incluindo a terra, giram sobre si próprios e à volta do Sol'(...) Como é que se pode explicar este extraordinário conhecimento científico? Sagan não duvidou um segundo que deve ter sido devido a um gaulês que atravessou aquelas paragens, e que provavelmente estava mais avançado do que a ciência da época (Lopes, 1995, p. 19-20).

\footnotetext{
${ }^{3}$ Dogon é um povo que habita o Mali e o Burkina Faso. São apenas 200 mil e a sua maioria vive em aldeias penduradas nas escarpas de Bandiagara, ao leste do Rio Níger.
} 
Concordando com Mignolo (2003), é possível afirmar, a partir do anteriormente apresentado, que o discurso da História do pensamento europeu é, de um lado, a História da modernidade europeia e, de outro, a História silenciada da colonialidade europeia.

A partir dessa compreensão da Colonialidade como raiz de um pensamento neutro, isento de compromissos engajados, entramos com algumas reflexões que nos mostra que o pensamento e a construção do conhecimento estão implicados com nossas aspirações normativas da realidade social.

\section{A militância e o conhecimento da realidade}

A ciência é uma das formas de compreender e construir a realidade. Assim como outras formas de compreensão do real, essa depende das perguntas que lançamos ao mundo. Por sua vez, as coisas do mundo se apresentam a nós de acordo com um determinado ponto de vista sobre elas, por exemplo: o elemento $\mathrm{H} 2 \mathrm{O}$ só se apresenta para nós neste modelo quando nos perguntamos “de que é feito a água?". Entretanto, para um pescador ou para uma lavadeira de roupas de beira de rio, essa pergunta não faz sentido. As perguntas são outras. Assim, as ciências revelam somente alguns aspectos do mundo que podem ser caracterizados como modelos, ou seja, uma teoria científica é um modelo construído para a representação de certos aspectos da realidade material humana.

O conhecimento sobre a realidade, portanto, é situado de acordo com as necessidades humanas. $\mathrm{O}$ ser humano não é determinado pelo seu organismo exclusivamente, como acontece com outros seres vivos, ele é livre, capaz de produzir e inventar coisas e, porque não dizer, realidades. E nesta produção se encontram as ciências, as artes, a religiosidade, a filosofia, os mitos, os símbolos etc.

As ciências ocupam um papel quase inquestionável nos tempos atuais, em quase todas as partes do planeta. Entretanto, o poder que a ciência tem deriva de sua capacidade de poder transformar ou até destruir o mundo. Embora seja um modelo de interpretação da realidade ou uma revelação de certos aspectos do mundo, os modelos científicos só são válidos se tiverem uma capacidade de previsibilidade e regularidade na explicação de determinados fenômenos. Em contrapartida, o imprevisível estabelece o caos, é cognoscível, mas não organiza a vida humana.

Há dimensões fundamentais no humano que não permitem nenhuma quantificação, previsibilidade ou estabelecimento de leis universais segundo um modelo científico das ciências naturais e matemáticas. Assim, o conhecimento do mundo requer acertos entre os indivíduos em sociedade, de acordo com a sua cultura e como foi socializado, ou como suas relações são institucionalizadas.

Duarte Junior (1984) conta a seguinte história, que nos serve para adentrar numa argumentação de como o conhecimento é construído a partir de um engajamento e desejabilidade dos indivíduos e das sociedades:

Num tempo em que os homens ainda não se alimentavam de carne de animais, um incêndio consumiu um bosque onde havia inúmeros porcos. Alguém que por ali passava, após a extinção das chamas, resolveu experimentar aqueles porcos assados e descobriu que eram palatáveis. Logo a notícia se espalhou e os homens passaram a comer porcos assados, que eram então preparados da maneira original, isto é, reuniram-se os animais num bosque e ateava-se fogo à vegetação. Esta instituição de cozimento de porcos foi crescendo e começaram a surgir especialistas: especialistas em tipos de bosques, em ventos, em atear fogo no setor norte, no setor sul, leste, oeste, especialistas em reflorestamento, especialista no ponto da mata em que os animais deveriam ser colocados, etc. enfim, toda uma parafernália para fazer progredir e aperfeiçoar a instituição criada. 
Realizavam-se então congressos anuais onde técnicas e inovações dentro de cada especialidade eram apresentadas e discutidas. Até que um dia um indivíduo procurou o presidente da organização e apresentou-lhe uma proposta que implicaria uma radical mudança na instituição, talvez o seu fim: bastaria que os porcos fossem mortos e colocados numa grelha, sob a qual se acenderia uma pequena fogueira. Imediatamente o presidente fez-lhe ver o absurdo de sua proposição, pois que ele geraria o desemprego para milhares de especialistas, além de abalar a confiança que o restante da sociedade manifestava com relação ao saber que eles detinham. Mostrou-lhe ainda que, pensando daquela maneira, revelava-se um perigoso elemento subversivo que poderia levar a sociedade ao caos, ainda mais ao propugnar métodos violentos que implicavam os homens matarem os animais com suas próprias mãos. O presidente então, num rasgo de "generosidade", disse ao dissidente que daquela vez ele seria perdoado, mas com a condição de nunca revelar a ninguém aquela ideia tão herética. E assim os homens continuaram a atear fogo nos bosques e a instituição foi mantida ( Duarte, 1984, p. 60-61).

Numa analogia com outros processos de invenção, podemos nos perguntar: até que ponto certas mudanças históricas, que provém de novos conhecimentos sobre a realidade, se efetivaram pela simples descoberta de algo novo? Será que não foi necessário o empenho e o engajamento de indivíduos e grupos sociais para que um novo conhecimento se estabeleça como hegemônica nas sociedades? Ou não seriam os interesses hegemônicos que perceberam que um novo conhecimento lhes garantiriam ainda mais poder e a partir disto se empenharam para realizarem mudanças?
No campo das ciências humanas e mesmo das ciências naturais, o pensamento requer o desejo de intervir no mundo. Não há simples constatações de algo dado. No avanço das ciências e do conhecimento sempre tivemos o empenho e o engajamento de indivíduos e coletivos. Nas pesquisas que produziram a máquina a vapor, o avião, os processos de combustão de petróleo, as investigações no âmbito da física, da genética, dentre outras, sempre foi necessário um engajamento e investimento de tempo e recursos para o desenvolvimento de procedimentos científicos e aprofundamento da compreensão humana. O sujeito do conhecimento sempre foi implicado com sua realidade, necessitou se empenhar para que seu conhecimento fosse aceito por outros, primeiro numa comunidade científica e em seguida por uma sociedade. Isso não é militância? Ou melhor, isso não significa ter uma postura de vida em que o sujeito luta por uma causa e dedica boa parte de sua vida na busca de seus objetivos?

Entretanto, há quem considere que o conhecimento está dado e basta descobri-lo, e há também quem considere que fazer militância política, social ou cultural não produz conhecimento, ou seja, se limita a ordem do discurso denunciativo ou da reprodução argumentativa de palavras que servem somente para marcar uma posição e para reivindicar algo de forma repetitiva. Por outro lado, se fizermos uma pesquisa sobre as principais invenções do mundo humano, em especial, do mundo das ciências humanas, veremos o quanto o pensamento e o conhecimento se estruturaram a partir de um engajamento, seja ele político, social, cultural etc.

Assim, partimos do pressuposto de que não é possível pensar o sujeito em ação de pesquisa e conhecimento sem sua implicação com o contexto político, social e cultural. Embora esta afirmativa não seja mais questionada veementemente pelas ciências humanas, há ainda uma herança positivista de crença que o conhecimento surge a partir da neutralidade axiológica, negando por sua vez que a militância, no sentido pleno do que afirmamos aqui, mudou o mundo e continuará mudando. 


\section{O engajamento produziu novas percepções sobre o real: racismo e antirracismo}

Partindo dos pressupostos que descrevemos acima, entramos numa reflexão singular que evidencia como a militância e o engajamento produzem conhecimento e novas compreensões sobre a realidade. Trata-se das relações raciais na sociedade brasileira, principalmente no que diz respeito a construção e formulação de conceitos e teorias, ou em outros termos, da enunciação epistêmica que se propõe a disputar espaços políticos contra os padrões hegemônicos de conhecimento.

Até meados do século XX a ideia de raça predominante no pensamento social brasileiro era aquela construída pelo colonialismo europeu, onde a expansão capitalista vem acompanhada das nascentes explicações antropológicas das diferenças fenotípicas, ou seja, o evolucionismo. O racismo científico ganha vida real nas teorias de Gobineau e Lombroso, pois cada "raça" deve ocupar seu lugar no mundo, no espaço permitido pela "raça branca" europeia.

Todorov (1993) aborda a época da produção teórica do racismo e do racialismo pretensamente científico no contexto intelectual francês do início do século XVIII ao início do século XX. Destaca inicialmente que, a partir das grandes navegações europeias no século $\mathrm{XV}$, aparecem as embrionárias elaborações eurocêntricas. Essas dão início à justificação ideológica do colonialismo nas Américas, na África e na Ásia.

Para Schwarcz (1993) essas formulações ganham destaque entre intelectuais no Brasil e se estabelece como argumento racial que foi política e historicamente construído neste período e amplamente assumido entre juristas, médicos, historiadores etc., de forma quase consensual, para responder a uma questão permanentemente levantada: que país é este?

Ao partir do pressuposto de que a ideologia racial brasileira foi elaborada por uma elite intelectual, Skidmore (1974) estuda as obras dessa elite entre
1870 e 1930 e conclui que essas obras deram o teor do pensamento social brasileiro, mesmo com reformulações a partir da obra de Gilberto Freyre e as formulações contestatórias surgidas posteriormente com Florestan Fernandes e outros.

A contribuição de Freyre, por exemplo, é ter demonstrado que negros e mestiços tiveram contribuições positivas na cultura e identidade nacional; entretanto, ao transformar a mestiçagem em valor positivo, e não negativo sob o aspecto da degenerescência, Freyre formula os contornos de uma identidade nacional que há muito tempo vinha sendo desenhada. Ou seja, ele consolida um mito de origem da sociedade brasileira, baseado na harmonia das três raças, onde, da dupla mistura - biológica e cultural brota lentamente o mito da democracia racial.

No campo da historiografia, também tivemos a predominância de uma construção teórica em que prevaleceu uma visão hegemônica da história contada a partir dos grandes feitos da civilização europeia, da racialização dos povos para a construção de uma nova nação. Clovis Moura (1990) vai destacar essa questão na seguinte afirmação:

(...) toda a nossa produção historiográfica, quer na colônia, no império e república, foi ferramenta ideológica dos senhores de escravos, no início, e, depois instrumento racionalizador da estrutura que se formou após a abolição, quando o negro egresso da senzala foi ocupar as grandes franjas marginalizadas que existem até hoje, sendo usado o preconceito de cor, subjacente, para justificar o imobilismo social em que a população negra e não-branca de um modo geral se encontra (p. 36).

A partir disto, se conformou no pensamento social e historiográfico brasileiro um paradigma racial que se consolidou como verdade, ou seja, de que existe uma democracia racial brasileira onde a mestiçagem ou mistura racial são as características de uma sociedade onde não existe o racismo. 
Segundo Munanga (1999), o discurso da mestiçagem foi uma estratégia inteligente das elites para evitar, tanto o aparecimento explícito do racismo quanto a dominação cultural branco-europeia. O autor afirma que no Brasil a miscigenação não foi voluntária, mas fator do desequilíbrio demográfico entre homens e mulheres brancas. $\mathrm{O}$ "mulato", afirma o autor, nasce de uma relação imposta pelo branco sobre a mulher negra e índia. Esse fator crescente de miscigenação imposta exerceu direta influência no pensamento social brasileiro e no imaginário popular. Entretanto, os terrores da escravidão, o mito da democracia racial, a teoria do embranquecimento e a miscigenação não foram suficientes para impedir o protesto negro, a resistência à opressão escravista e à hegemonia branca na construção da identidade nacional a partir do final do século XIX e início do XX. E nesse espectro é que destacamos como os movimentos de resistência e afirmação negra - sob variadas formas - iniciaram a partir dos anos de 1970 uma disputa política e epistêmica que conforma, atualmente, novos conceitos e novos conhecimentos sobre a realidade racial brasileira.

A resposta dos movimentos sociais negros a este conhecimento hegemônico foi ressignificar os conceitos de raça, negro e formular uma crítica profunda da ideia de democracia racial. Por outro lado, ao propor essas ressignificações, o movimento negro e seus intelectuais forjaram um novo campo de estudos e pesquisas com as propostas de ações afirmativas, a reescrita da história racial brasileira e dos estudos africanos.

Anterior ao período que destacamos (década de 1970), a população negra construiu seus mecanismos de resistência e afirmação como uma vasta imprensa negra no início do século XX, a Frente Negra Brasileira (FNB), o Teatro experimental do Negro (TEN), além de vários encontros e congressos em que se debatiam e se formularam propostas sobre cultura, religiosidade e educação. Na década de 1970, foi fundado o Movimento Negro Unificado (MNU) que, para muitos pesquisadores, representou um marco de luta $\mathrm{e}$ formulação de novos olhares para a realidade brasileira. O objetivo desse movimento era o de desenvolver instrumentos de luta contra a opressão policial, o desemprego e a marginalização da comunidade negra. O MNU tinha inicialmente no seu programa básico de ação, a desmistificação da democracia racial brasileira; a organização política dos "afro-brasileiros" para transformá-la em movimento de massas; a busca de alianças com outros grupos voltados para a luta contra o racismo; a organização em partidos políticos e sindicatos, além do apoio à luta internacional contra o racismo.

Esses movimentos, segundo Moura (1983), despertaram intelectuais negros, profissionais liberais, estudantes, funcionários públicos e negros pobres no Brasil, a partir do final da década de 70, a se conscientizarem da necessidade de se auto afirmarem como negros. Essa construção ocorre na contramão do processo de embranquecimento e da hegemonia do mito da democracia racial. Portanto, o movimento ganha força e aparecem slogans como "negro é lindo", "não deixe sua cor passar em branco" etc. Na esteira dessas novas construções, é que o Movimento Negro, na década de 90, consegue transformar o 13 de maio em Dia Nacional de Denúncia Contra o Racismo. Evai além: institui a Semana Nacional da Consciência Negra, estabelecendo o 20 de novembro, como comemoração da resistência e da morte do "herói negro" nacional Zumbi dos Palmares.

De "cor preta" ou "negro" como terminologia pejorativa, o movimento, ainda de forma incipiente, consegue ressignificar a categoria "negro" como símbolo de uma condição étnica e racial. A "raça” também é ressignificada, não se tratando mais de uma noção biológica, mas política, ou seja, "raça negra" como um conjunto de indivíduos que possuem histórias e culturas comuns, no passado e no presente.

Toda esta construção conceitual, ou seja, "consciência negra", "negro" e "raça" como expressão de uma política identitária pode ser caracterizada na perspectiva de um pensamento crítico de fronteira (Walsh, 2005) que significa tornar visível outras lógicas e formas de pensar, diferentes da lógica eurocêntrica e dominante. Pois, estas reconceitualizações, partem da perspectiva das experiências subalternizadas pela colonização europeia. 
Nesse sentido, as ressignificações promovidas pelos movimentos negros, propiciam aquilo que Mignolo (2003) denomina de diferença colonial, ou seja, pensar a partir das ruínas, das margens criadas pela colonialidade do poder, das experiências e histórias subalternizadas. Não se trata aqui de resgate de autenticidades identitárias, mas sim de uma operação conceitual a partir de um lócus específico de enunciação, marcada pela opressão, discriminação e racismo contra aqueles considerados não brancos. Algumas formulações dos movimentos negros, nos anos seguintes, evidenciarão a possibilidade concreta da emergência de uma razão subalterna, ou seja, um conjunto diverso de práticas teóricas que emergem em determinados contextos em resposta aos legados coloniais e dialogando com estes.

O conceito de raça com base biológica, além de ter sido desmistificada pelos estudos genéticos nos anos de 1990, foi profundamente ressignificado pelos movimentos negros, pois raça passou a ser utilizada como denúncia e proposição de uma interpretação da realidade brasileira, ou seja, que embora o conceito de raça não exista cientificamente ou naturalmente, ele existe social e historicamente.

Se os homens de ciência (também militantes de uma visão hegemônica de sociedade) ajudaram a produzir as pseudo-teorias raciais que atestavam uma suposta inferioridade e superioridade racial, por outro lado, ao final do século XX, os movimentos sociais negros e seus aliados, indagaram a ciência por dentro e problematizaram conceitos, categorias e teorias que as colocavam como meras categorias analíticas (axiologicamente neutras), e as colocaram em outro lugar, isto é, compreendendo-as como construção social, cultural e eminentemente política. Em outros termos, os movimentos negros e seus aliados

Ao elegerem a ressignificação da raça, como categoria útil de análise para entender as relações raciais, colocam-se no terreno político e epistemológico de desconstrução mental, ressignificação e descolonização de conceitos e categorias. Ao tematizarem a raça como construção social, cultural, histórica e política, ao discutirem que a incidência do racismo sobre os negros (pretos e pardos) não se restringe à sua ascendência africana e nem à sua cultura, mas está vinculada às interpretações que recaem sobre os sinais diacríticos inscritos no corpo negro, os intelectuais negros re-politizam a raça e resemantizam-na (Gomes, 2009, p. 429-430).

Neste sentido, a crítica teórica não se reduz a uma mera interpretação da realidade racial brasileira baseado em teorias específicas ou um rol de conceitos, mas também na produção de um novo conhecimento que tem como objetivo a contestação de acomodadas análises científicas que fundamentam o mito da democracia racial. Neste sentido, evidencia-se, com o crescimento do respaldo dessas análises na academia brasileira, por exemplo, que ocorre uma militância como forma de produção de conhecimento "que não se esgota em si mesmo, mas propõe reflexões teóricas que induzem ações emancipatórias e de transformação da realidade" (GOMES, 2009, p. 433).

Com estas críticas e formulações teóricas constatamos que a reflexão sobre relações raciais no Brasil no atual contexto, e com a força das ações dos movimentos sociais negros, também estabeleceu uma nova agenda de discussão governamental, não somente com um assunto novo, mas promovendo a constituição de novos sujeitos que produzem conhecimentos fora da lógica da matriz conceitual europeia.

\section{Enfim...sem engajamento e militância, não há pensamento que avance}

A produção deste texto surge a partir de uma longa trajetória de militância política e acadêmica, na qual, cotidianamente, nos vimos interpelados por pares e estudantes universitários acerca de nossa produção de conhecimento que entrelaça militância antirracismo e estudos acadêmicos. Sempre indagados e muitas vezes questionados, sentimos necessidade de iniciar uma 
reflexão coletiva sobre a produção de conhecimento a partir de um determinado engajamento político antirracismo.

Mas esta reflexão não se constitui como novidade. Hooks (2013) e Freire (1987) nos inspiram a reflexão de que um intelectual militante das ciências humanas não realiza a simples produção de técnicas para o convívio social. Ou ele faz política posicionada ou a pseudo política da neutralidade que, no nosso entendimento, é também posicionada.

Se os homens [e as mulheres] são seres do quefazer é exatamente porque seu fazer é ação e reflexão. É práxis. É transformação do mundo. E na razão mesma, em que o quefazer é práxis, todo fazer do quefazer tem de ter uma teoria que necessariamente o ilumine. $\mathrm{O}$ quefazer é teoria e prática. É reflexão e ação. (FREIRE, 1987, p. 145)

Em outros termos poderíamos acrescentar que a prática da militância (a ação sobre o mundo) constitui uma unidade dinâmica com a produção teórica sobre esse mesmo mundo, ou nos termos de Hooks (2013), um engajamento mediado por uma determinada pedagogia.

Quando o trabalho intelectual surge de uma preocupação com a mudança social e política radical, quando esse trabalho é dirigido para as necessidades das pessoas, nos põe numa solidariedade e comunidade maiores. Enaltece fundamentalmente a vida (HOOKS, 1995, p. 478).

A prática social dos movimentos negros no final do século XX interferiu decisivamente no sentido de ressignificar o conhecimento hegemônico sobre relações raciais no Brasil, colocando em questão aquelas teorizações que moldavam "cientificamente" o sistema de classificação racial, embasado em conceitos e teorias legitimadas academicamente. $\mathrm{O}$ que fez esse cenário mudar foi a militância política dos negros e negras ao longo do século XX e agora no século XXI.
O sujeito epistêmico subalternizado sempre esteve presente na história colonial brasileira e mesmo com o advento do Brasil como nação independente. Entretanto, como vimos com a reflexão sobre a Colonialidade do saber, esse sujeito foi invisibilizado e colocado à margem dos processos de construção de conhecimento considerado válido, e ainda, classificado como possuidor de conhecimentos fora da dimensão racional de pensamento. Porém, quando este sujeito se ergue, com suas aspirações e formulações sobre a realidade, ele é classificado por uma comunidade epistêmica dominante como um "simples" militante, ou, repetindo: se limita a ordem do discurso denunciativo ou da reprodução argumentativa de palavras que servem somente para marcar uma posição e para reivindicar algo de forma repetitiva.

Esta reflexão não para por aqui, pois gostaríamos com este texto abrir uma agenda de discussão que nos permita avançar no conhecimento da realidade, pois entendemos que este mesmo conhecimento foi, e sempre será, devedor de homens e mulheres que se engajam na luta permanente por um outro mundo possível.

\section{Referências bibliográficas}

Hooks, B. (2013). Ensinando a transgredir. A educação como prática da liberdade. São Paulo: Ed. Martins fontes.

_.. (1995) Intelectuais Negras. Estudos feministas. n. 3 (2), p. 464-478. Castro-Gómez, S. (2005). La poscolonialidad explicada a los niños. Bogotá: Editorial Universidad Javeriana.

Duarte, João Francisco. (1984) O que é realidade. São Paulo: Brasiliense.

Dussel, E. (1990). El último Marx (1863-1882) y la liberación latinoamericana. México: Siglo XXI. 
. (2009). Meditações anti-cartesianas sobre a origem do anti-discurso filosófico da modernidade. In: Santos, B. y Meneses, M. (Orgs.) (2009). Epistemologias do Sul. Coimbra: Edições Almedina, p. 283-335.

Freire, P. (1987). Pedagogia do oprimido. Rio de Janeiro: Paz e Terra.

Gomes, N. (2009) Intelectuais negros e produção do conhecimento: algumas reflexões sobre a realidade brasileira. In: Santos, B. y Meneses, M. (Orgs.) (2009). Epistemologias do Sul. Coimbra: Edições Almedina, 2009, p. 419441.

GrosfogueL, R. (2007). "Dilemas dos estudos étnicos norte-americanos: multiculturalismo identitário, colonização disciplinar e epistemologias descoloniais". Ciência e Cultura. São Paulo: v. 59, nº. 2, p. 32-35.

Hegel, F. (1970). Obras completas. Frankfurt: Suhrkamp Verlag.

Lopes, C. (1995). A pirâmide invertida. Historiografia africana feita por africanos. In: Actas do Colóquio Construção e Ensino da História da África. Lisboa: Linopazes, 1995.

Mignolo, W. (2003). Histórias Globais projetos Locais. Colonialidade, saberes subalternos e pensamento liminar. Belo Horizonte: Ed. UFMG.

MOURA, C. (1983) Brasil: raízes do protesto negro. São Paulo: Global.

- (1990). As injustiças de Clio. O negro na historiografia brasileira. Belo Horizonte: Oficina do livro.

Munanga, K. (1999) Rediscutindo a mestiçagem no Brasil. Petrópolis: Vozes.
Praxedes, W. (2008). "Eurocentrismo e racismo nos clássicos da filosofia e das ciências sociais". Revista Eletrônica Espaço Acadêmico. 2008, Disponível em www.espacoacademico.com. br/.../83praxedes.htm

Quijano, A. (1992) Colonialidad y modernidadracionalidad. In: Bonilla, H. (Org.) (1992). Los conquistadores. Bogotá: Tercer Mundo, p. 437-447.

Schwarcz, L. (1993). O espetáculo das raças. Cientistas, instituições e questão racial no Brasil 1870 - 1930. São Paulo: Cia das Letras.

Skidmore, T. (1974). Preto no Branco. Raça e nacionalidade no pensamento brasileiro. Rio de Janeiro: Paz e Terra,

Todorov, T. (1993). Nós e os outros: a reflexão francesa sobre a diversidade humana. Rio de Janeiro: Jorge Zahar Editor.

Walsh, C. (Orgs.) (2005). Pensamiento crítico y matriz (de)colonial. Reflexiones latinoamericanas. Quito: Ediciones Abya-yala.

Weber, M. (1992). The protestant Ethics and the spirit of capitalism. New York: Routledge. 